\title{
The mediating effect of social support on uncertainty in illness and quality of life of female cancer survivors: a cross-sectional study
}

\author{
Insook Lee ${ }^{1^{*}}$ (D) and Changseung Park ${ }^{2}$
}

\section{Background}

Cancer survivors have been defined as those living more than 5 years after cancer treatment with no signs of recurrence or further growth; however, the National Coalition for Cancer Survivorship of the United States defined cancer survivors as those undergoing treatment after being diagnosed with cancer or those considered to be fully cured. The National Cancer Institute of the United States established the Office of Cancer Survivorship, with the American Society of Clinical Oncology including "patient and survivor management" as its 2006 annual objective [1], indicating the importance of cancer survivor management as a major agenda item.

Typically, breast and thyroid cancer diagnoses occur among women in their 40s and 50s, and patients who receive treatment have high survival rates. The majority of breast and thyroid cancer survivors return to their daily lives within a relatively short timeframe [2], making quality of life after treatment and important factor in cancer treatment [3-5].

Cancer survivors have reported experiencing a variety of physical difficulties during or after treatment, including fatigue, pain, loss of energy, sleeping disorders, and constipation $[6,7]$. They also have psychological concerns, such as fear of the cancer spreading, concerns about treatment results, and uncertainty about the future [8], as well as financial difficulties, issues with their sex lives, decreased body image, difficulties in interpersonal relationships, role disorders, and difficulty

*Correspondence: dobest75@changwon.ac.kr; dobest75@gmail.com 'Department of Nursing, Changwon National University, C.P.O. Box 51140, Changwon, Republic of South Korea

Full list of author information is available at the end of the article returning to work [7]. Thus, cancer patients require a diverse range of healthcare services, plus emotional and socioeconomic support, with an international study of the quality of life and symptoms of cancer survivors reporting that the quality of life among Asian patients to be the lowest of those than other country [6]. Survivors of breast cancer have reported low quality of life after treatment $[9,10]$, which is influenced by emotional and psychological factors such as uncertainty, body image, lack of self-respect, and depression [9-11], as well as social factors including social, family, and spouse support $[10,11]$.

Uncertainty among women diagnosed with malignant illnesses was found to be higher than that among women with a lump in the breast [12]. Uncertainty among breast cancer patients continues for a long period because of the fear of recurrence [13] and reduced quality of life [11]. Similarly, thyroid cancer survivors also show higher levels of fatigue, depression, and anxiety compared to those with no experience of cancer [14-16].

Social support is a complex and multidimensional concept that is characterized by mutual benefits that include social, psychological, and material support provided by the social support network [17]. In other words, social support means help provided by social relationships such as family, friends, and significant others, and plays an important role in directly and indirectly reducing uncertainty $[18,19]$. For cancer survivors, the need for social support is varied and depends largely on the adaptive tasks they face [20]. Social support is closely related to breast cancer survivor prognosis [21]; breast cancer survivors' uncertainty was found to lower their quality of life, but their recognition of social support was 
found to improve it [11]. Recognition of social support and uncertainty played a key role in managing and maintaining quality of life. Research has shown that social support differs according to survival stage, as patients who are undergoing treatment receive active support from healthcare professionals and their family, but this support declines notably after the treatment ends [14, 22, 23].

With the number of cancer survivors steadily increasing, there has been an increase in the number of studies published on cancer survivors internationally [22, 24]. In Korea in particular, there have been studies on recurrence-prevention behaviors and quality of life [25], the factors influencing quality of life [10], fatigue and quality of life [26], distress and quality of life [27], and symptoms and quality of life among breast cancer survivors [8]. Most of these studies focused on breast cancer survivors, but few studies focus on overall quality of life and the related influential factors. Few studies have analyzed the relationships between uncertainty in illness, quality of life, and social support among female breast and thyroid cancer survivors.

\section{Methods}

\section{Aims}

This study aimed to identify the relationships among uncertainty in illness, social support, and quality of life in female cancer survivors, and to verify the mediating role of social support, in the relationship between uncertainty in illness and quality of life. Social support may act as a generative mechanism influencing how uncertainty in illness, the predictor variable, affects quality of life, the outcome variable (Fig. 1) [28]. Therefore, this study will provide foundational data for devising practical and helpful intervention strategies to raise the quality of life of cancer survivors.

\section{Participants}

Participants were selected using convenience sampling of female cancer patients who were being treated by specialists in breast endocrinology at general hospitals located in J City of Korea. Among the 189 women (138 thyroid and 50 breast cancer patients) who agreed to participate, 156 surveys were collected (response rate: 82.5\%). The final sample including 148 participants after excluding eight insincere responses. The data collection period was from April 21 to June 30, 2014. The completion of data collection through the mailed-in copies of surveys occurred on October 15, 2014. Participants were asked to complete the survey, put it in an opaque envelope, and seal it before returning it to the researchers. In cases in which on-site survey completion was difficult, participants were able to complete the survey at home and returned it by mail to the researcher.

The necessary sample size for the multiple regression analysis was confirmed utilizing G*power ver. 3.1.9 with a significance level $(\alpha)$ of .05 ; power of .80 ; effect size $\left(f^{2}\right)$ of .15 (representing a medium effect size in the multiple regression analysis); and 13 independent variables (age, marital status, religion, level of education, occupation, satisfaction with economic status, smoking, drinking, diagnosis name, clinical stage of cancer, time passed since the end of treatment, uncertainty, and social support). The minimum sample size was determined to be 131. Since a maximum dropout rate of $40 \%$ was expected, information was collected from a total of 189 participants who fit the following inclusion criteria: 1) a diagnosis of cancer and no cognitive limitations; 2) the ability to understand and complete the survey in Korean; and 3) an understanding of the purpose of the study and consenting to participate. The exclusion criteria were those suffering from a mental illness, those with difficulties in communication, and those who did not wish to participate in the study.

\section{Measures}

\section{Uncertainty in illness}

Uncertainty occurs when an appropriate subjective interpretation of an illness or event is not formed. This study measured uncertainty using Mishel's Uncertainty in

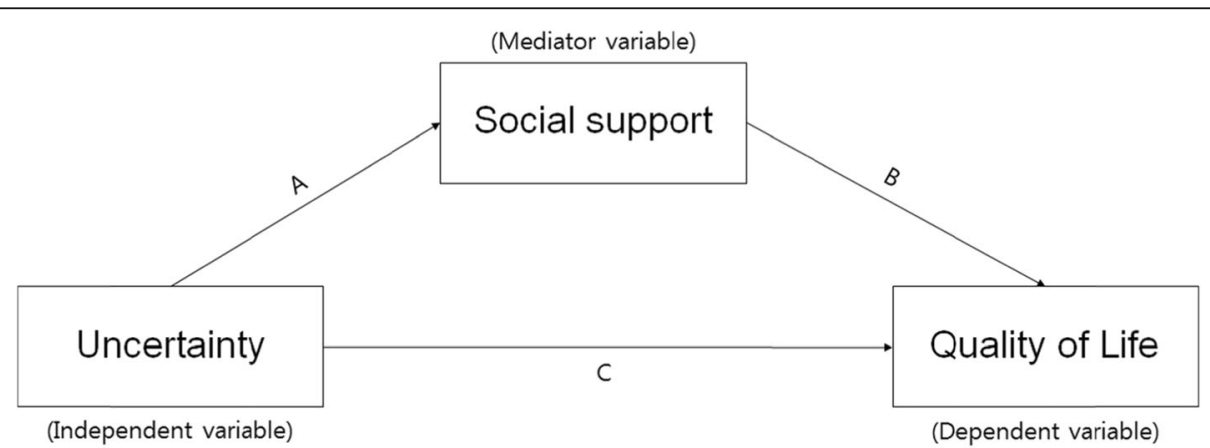

Fig. 1 The theoretical research model showing the influence of uncertainty on quality of life and the mediating effect of social support 
Illness Scale (MUIS), which is composed of 33 items concerning uncertainty in illness. Mishel [19] originally developed the scale, and it has been translated into Korean by Lee [28]. The MUIS is a self-administered survey, with items scored on a 5-point scale from 5 (strongly agree) to 1 (strongly disagree). Positive items were measured backward, so that total scores ranged from 33 to 165 . Higher scores indicated higher rates of uncertainty. The Cronbach's $\alpha$ for the original 33-item tool was .91-.93; the Cronbach's $\alpha$ for the tool used in the study of Korean breast cancer patients [29] was .83. In this study, the Cronbach's $\alpha$ for the uncertainty scale was .88

\section{Social support}

Social support was measured using Zimet et al.'s [30] Multidimensional Scale of Perceived Social Support (MSPSS). This 12-item measure is scored on a 7-point, Likert-type scale, and assessed the three dimensions of family, friends, and significant others. Its sub-domains are composed of four items. Overall social support scores are calculated by summing the scores for each item, with higher scores indicating higher levels of social support. At the time of development, the Cronbach's $\alpha$ reliability was .91; Cronbach's $\alpha$ for each subscale ranged from .90-.95. In this study, the Cronbach's $\alpha$ of the social support scale was .95 .

\section{Quality of life}

Quality of life was measured using a standardized tool that was translated into the Korean and verified validity of the Korean version of the EORTC QLQ-C30, which was developed through a process of international joint study from multiple countries, and it is the most widely used standardized tool to measure the quality of life of cancer patients. This tool is composed of three subdomains and 30 items. It includes two items on overall quality of life and five functional domains (i.e., physical, role, cognitive, emotional, and social functions) that include 15 items; three symptom domains (i.e., fatigue, pain, nausea/vomiting) that include seven items; and one item for each of the symptoms commonly reported by cancer patients (i.e., difficulties in breathing, loss of appetite, sleeping disorders, constipation, diarrhea, and financial hardship) [31]. The EORTC QLQ-C30 is converted into a score ranging between 0 and 100 points [31]; higher overall quality of life scores, higher functional domain scores, and lower symptom domain scores indicate higher quality of life. Moreover, overall quality of life can be understood as a measurement of comprehensive quality of life [31]. This study assess quality of life using the overall quality of life score. At the time of development, Cronbach's $\alpha$ was .65-.73; the Cronbach's $\alpha$ for the overall quality of life score in this study was .853 .

\section{Ethical considerations}

This study was conducted after receiving approval of the research protocol from the Institutional Review Board (Approved number: 2014-L02-01). The purpose and method of the research was explained directly to participants by a trained research assistant. The participants then signed an informed consent form that stated the survey would be used for the purposes of the study only, and that their confidentiality would be safeguarded. The subjects who agreed to participate in the survey received a small amount of goods worth of KRW 3000, but there were no factors that could interfere with the answers in the survey.

\section{Data analysis}

The collected data were coded and analyzed using SPSS software (version 24.0; SPSS Inc., Chicago, IL) at .05 significance level. The analysis excluded missing data values. The general characteristics, illness-related characteristics, uncertainty, social support, and quality of life were measured using frequency, percentages, means, and standard deviations. The differences in uncertainty, social support, and quality of life in accordance with general and illness-related characteristics were analyzed using independent $t$-tests and one-way analysis of variance (ANOVA). Tukey's post-hoc analysis was used for independent variables of more than three groups to identify which group contained the differences. Pearson's correlation coefficient was calculated to identify correlations between uncertainty, social support, and quality of life. Multiple regression (stepwise method) was used to test the influence of uncertainty on social support and quality of life. To verify the mediating effects of social support in the relationship between uncertainty and quality of life, simple, and hierarchical multiple regression analyses were conducted as per the method proposed by Baron and Kenny [30]. The significance of the mediating effects of social support was verified using the Sobel test.

\section{Results}

\section{Demographic characteristics of subjects}

The general characteristics of the female cancer survivors in this study indicated that their average age was $51.87(S D=11.78)$ years, with the largest proportion (33.3\%) of the population being in their 50s, followed by those in their $40 \mathrm{~s}(30.1 \%), 60 \mathrm{~s}$ and over $(24.4 \%)$, and below $30(12.2 \%)$. Most participants $(76.2 \%)$ were married; $61.9 \%$ practiced a religion, and $66.7 \%$ had a high school education or below; $56.2 \%$ had jobs; $17.8 \%$ had lost their jobs as a result of their cancer diagnosis and 
treatment, and $73.1 \%$ indicated that their satisfaction with their financial status was average. They had an average of $2.26(S D=1.19)$ children; $94.4 \%$ were nonsmokers; $64.1 \%$ were non-drinkers; $29.1 \%$ of the subjects had breast cancer and $70.9 \%$ had thyroid cancer; $53.8 \%$ of the cancers were early stage, and $46.2 \%$ were advanced. The duration after cancer treatment averaged $17.64(S D=31.30)$ months, with $70.3 \%$ reporting a duration of less than a year since they ended their treatment (Table 1).

Uncertainty in illness, social support, and quality of life Average scores of uncertainty in illness, social support, and quality of life are given in Table 2 . The average uncertainty in illness score was $83.06(S D=15.29$; range: 44-127 points), and the average quality of life score was 66.90 ( $S D=20.32$; range: $0-100$ points). Average social support score was $62.62(S D=17.09$; range: $12-84$ points), with family support being the highest (mean = 21.84, $\mathrm{SD}=6.58)$, followed by support from significant others $($ mean $=21.28, S D=5.93)$ and friends (mean $=$ 19.45, $S D=6.70)$.

Differences in uncertainty in illness, social support, and quality of life according to general and illness-related characteristics

The results of the analysis of differences in uncertainty in illness, social support, and quality of life according to

Table 1 Participants' demographic and illness-related characteristics. $N=148$

\begin{tabular}{|c|c|c|c|}
\hline Variable & Category & Frequency & $\%$ \\
\hline \multirow[t]{4}{*}{ Age (years) } & Below 40 & 15 & 12.2 \\
\hline & $40-49$ & 37 & 30.1 \\
\hline & $50-59$ & 41 & 33.3 \\
\hline & 60 and over & 30 & 24.4 \\
\hline \multirow[t]{3}{*}{ Marital status } & Married & 7 & 4.8 \\
\hline & Single & 112 & 76.2 \\
\hline & Widowed or divorced & 28 & 19.0 \\
\hline \multirow[t]{2}{*}{ Education } & Less than high school & 92 & 66.7 \\
\hline & University and higher & 46 & 33.3 \\
\hline \multirow[t]{2}{*}{ Religion } & No & 56 & 38.1 \\
\hline & Yes & 91 & 61.9 \\
\hline \multirow[t]{3}{*}{ Having a job } & No & 38 & 26.0 \\
\hline & Loss of job & 26 & 17.8 \\
\hline & Yes & 82 & 56.2 \\
\hline \multirow[t]{3}{*}{ Satisfaction with economic status } & Satisfaction & 9 & 6.2 \\
\hline & Average & 106 & 73.1 \\
\hline & Dissatisfaction & 30 & 20.7 \\
\hline \multirow[t]{3}{*}{ Number of children } & No or 1 & 27 & 18.4 \\
\hline & 2 & 70 & 47.6 \\
\hline & 3 and over & 50 & 34.0 \\
\hline \multirow[t]{2}{*}{ Smoking status } & Current smoker & 8 & 5.6 \\
\hline & Non-smoker & 135 & 94.4 \\
\hline \multirow[t]{2}{*}{ Drinking status } & Current drinker & 52 & 35.9 \\
\hline & Non-drinker & 93 & 64.1 \\
\hline \multirow[t]{2}{*}{ Type of cancer } & Breast cancer & 43 & 29.1 \\
\hline & Thyroid cancer & 105 & 70.9 \\
\hline \multirow[t]{2}{*}{ Stage of cancer } & Early-stage cancer & 71 & 53.8 \\
\hline & Advanced stage cancer & 61 & 46.2 \\
\hline \multirow[t]{3}{*}{ Time since completion of cancer treatment (years) } & Less than 1 & 104 & 70.3 \\
\hline & $1-5$ & 32 & 21.6 \\
\hline & 5 or more & 12 & 8.1 \\
\hline
\end{tabular}


Table 2 Descriptive statistics for uncertainty in illness, social support, and quality of life. $N=148$

\begin{tabular}{llllll}
\hline Variable category & & Mean & SD & Possible range & Observed range \\
\hline Uncertainty in illness & & 83.00 & 15.29 & $33-165$ & $44-127$ \\
Social support & Family & 21.84 & 6.58 & $4-28$ & $4-28$ \\
& Friends & 19.45 & 6.70 & $4-28$ & $4-28$ \\
& Significant others & 21.28 & 5.93 & $4-28$ & $4-28$ \\
& Total & 62.62 & 17.09 & $12-84$ & $12-84$ \\
QoL & General QoL & 66.90 & 20.32 & $0-00$ & $0-100$ \\
\hline
\end{tabular}

Notes. SD, standard deviation, QoL Quality of Life

general and illness-related characteristics are given in Tables 3 and 4. There were significant differences in uncertainty in illness by educational level $(t=4.048$, $p<.001)$, satisfaction with financial status $(F=3.760$, $p=.027)$, and smoking $(t=2.195, p=.030)$. Uncertainty in illness was higher for subjects with less than a high school education, compared to those who had a university degree or higher, when they were dissatisfied with their financial status. Likewise, it was higher for smokers, compared to non-smokers.

Social support had statistically significant differences given satisfaction with financial status $(F=5.151, p=.007)$ and duration since cancer treatment completion $(F=$ 4.292, $p=.015$ ). Social support was higher for subjects with average financial status satisfaction, and for subjects for whom it had been less than a year, or between 1 to 5 years, since they completed cancer treatment.

Quality of life significantly differed according to financial status satisfaction $(F=6.648, p=.002)$. Participants had higher quality of life when they had high or average financial status satisfaction compared to dissatisfaction.

\section{Correlation between uncertainty in illness, social support, and quality of life}

The results of the correlation analyses indicated that uncertainty in illness had a significant negative correlation with social support $(r=-.335, p<.001)$ and quality of life $(r=-.312, p<.001)$; social support had a significant positive correlation with quality of life $(r=.321, p<.001)$. Correlations between the sub-factors of social support and quality of life indicate that there were significant positive correlations between quality of life and support from significant others $(r=.315, p<.001)$, friends $(r=.284, p=.001)$, and family $(r=.265, p=.001)$. Uncertainty and support from significant others $(r=-.326$, $p=.001)$, friends $(r=-.294, p=.002)$, and family $(r=$ $-.244, p=.010)$ showed significant negative correlations; particularly, the highest correlation was between support from significant others and uncertainty (Table 5).

\section{Mediating effect of social support}

Four stages of regression analysis were conducted to verify whether social support had mediating effects in the process by which uncertainty in illness influenced quality of life. Prior to verifying the mediating effects of social support, this study examined the multicollinearity between variables. The residual limit was between $0.8-1.0$, which is higher than 0.1 ; and the value of the variance inflation factor was between 1.0-1.2, which was lower than 10, indicating no issues with multicollinearity. Moreover, the Durbin-Watson test, which is the test of independence of residual error, indicated $\mathrm{d}=1.903$ 1.944, which was close to two and met the independence condition, representing no issues with self-correlation.

Using the hierarchy regression, this confirmed the partial mediating effects of social support in the process of uncertainty influencing quality of life (Table 6, Fig. 2). The first regression analysis indicated that the independent variable (uncertainty) had a statistically significant influence on the mediator variable (social support; $\beta=-$ $0.335, p<.001$ ), and the explanatory power for social support was $10.4 \%$. The second stage regression analysis indicated that the mediator variable (social support) had a significant influence on the dependent variable (quality of life; $\beta=0.321, p<.001$ ), and the explanatory power for quality of life was $9.7 \%$. The third stage regression analysis indicated that the independent variable (uncertainty) had a significant influence on the dependent variable (quality of life; $\beta=-0.312, p=.001$ ) with an explanatory power of $8.9 \%$. At the fourth stage, this study aimed to test the influence of the independent variable (uncertainty) on the dependent variable (quality of life) with social support as the mediator variable. The results indicated that uncertainty $(\beta=-0.241$, $p=.014)$ and social support $(\beta=0.213, p=.030)$ were significant predictors of quality of life. When social support was set as the mediator variable, uncertainty was found to have a significant influence on quality of life; the unstandardized regression coefficient reduced from -0.396 to -0.398 , indicating a partial mediation of social support. The explanatory power of these variables in terms of quality of life was $12.1 \%$. This study executed the Sobel test to verify the significance of the mediating effects of social support, confirming that they were significant in the relationship between uncertainty and quality of life. 
Table 3 Differences in uncertainty in illness and social support according to demographic and illness-related characteristics. $(N=148)$

\begin{tabular}{|c|c|c|c|c|c|c|c|}
\hline \multirow[t]{2}{*}{ Variable } & \multirow[t]{2}{*}{ Category } & \multicolumn{3}{|c|}{ uncertainty in illness } & \multicolumn{3}{|c|}{ social support } \\
\hline & & Mean & $S D$ & $\begin{array}{l}\boldsymbol{t} \text { or } \boldsymbol{F} \\
(\boldsymbol{p} \text { - value) }\end{array}$ & Mean & $S D$ & $\begin{array}{l}\boldsymbol{t} \text { or } \boldsymbol{F} \\
(\boldsymbol{p} \text {-value) }\end{array}$ \\
\hline \multirow[t]{4}{*}{ Age (years) } & Below 40 & 77.54 & 15.10 & 1.696 & 66.27 & 14.14 & 0.955 \\
\hline & $40-49$ & 78.62 & 15.70 & (.174) & 64.87 & 17.26 & $(.416)$ \\
\hline & $50-59$ & 84.62 & 15.61 & & 59.13 & 18.83 & \\
\hline & 60 and over & 86.71 & 15.08 & & 61.45 & 18.46 & \\
\hline \multirow[t]{3}{*}{ Marital status } & Married & 66.75 & 13.94 & 2.479 & 72.43 & 10.97 & 1.597 \\
\hline & Single & 83.91 & 15.52 & (.089) & 62.63 & 17.07 & $(.206)$ \\
\hline & Widowed or divorced & 82.68 & 13.06 & & 59.61 & 17.92 & \\
\hline \multirow[t]{2}{*}{ Education } & Less than high school & 86.87 & 13.87 & 4.048 & 62.73 & 17.19 & -0.207 \\
\hline & University and higher & 75.16 & 14.67 & $(<.001)$ & 63.37 & 16.43 & $(.836)$ \\
\hline \multirow[t]{2}{*}{ Religion } & No & 82.08 & 14.98 & -0.387 & 62.75 & 19.19 & 0.060 \\
\hline & Yes & 83.28 & 15.45 & $(.699)$ & 62.57 & 15.83 & $(.952)$ \\
\hline \multirow[t]{3}{*}{ Having a job } & No & 86.45 & 14.99 & 1.213 & 62.22 & 14.70 & 0.304 \\
\hline & Loss of job & 84.22 & 12.31 & $(.301)$ & 65.12 & 14.85 & (.738) \\
\hline & Yes & 81.17 & 16.29 & & 62.20 & 18.85 & \\
\hline \multirow[t]{3}{*}{ Satisfaction with economic status } & Satisfaction ${ }^{a}$ & 72.38 & 15.57 & 3.760 & 66.56 & 13.88 & 5.151 \\
\hline & Average $^{b}$ & 82.65 & 14.68 & $(.027)$ & 64.94 & 15.80 & $(.007)$ \\
\hline & Dissatisfaction $^{c}$ & 89.10 & 15.95 & $a<c$ & 54.07 & 20.39 & $b>c$ \\
\hline \multirow[t]{3}{*}{ Number of children } & No or 1 & 81.00 & 20.06 & 0.408 & 62.19 & 20.02 & 0.056 \\
\hline & 2 & 84.45 & 13.24 & $(.666)$ & 62.49 & 16.89 & $(.945)$ \\
\hline & 3 and over & 82.31 & 15.40 & & 63.38 & 14.49 & \\
\hline \multirow[t]{2}{*}{ Smoking status } & Current smoker & 96.80 & 20.03 & 2.195 & 48.63 & 27.02 & -1.540 \\
\hline & Non-smoker & 81.77 & 14.70 & $(.030)$ & 63.50 & 16.29 & $(.166)$ \\
\hline \multirow[t]{2}{*}{ Drinking status } & Current drinker & 84.95 & 16.30 & 1.301 & 63.78 & 18.00 & 0.591 \\
\hline & Non-drinker & 81.03 & 14.30 & (.196) & 62.00 & 16.90 & $(.556)$ \\
\hline \multirow[t]{2}{*}{ Type of cancer } & Breast cancer & 82.71 & 15.94 & -0.140 & 66.77 & 14.09 & 1.911 \\
\hline & Thyroid cancer & 83.19 & 15.16 & $(.889)$ & 60.89 & 17.97 & $(.058)$ \\
\hline \multirow[t]{2}{*}{ Stage of cancer } & Early-stage cancer & 82.76 & 14.26 & -0.490 & 64.13 & 13.66 & 0.241 \\
\hline & Advanced stage cancer & 84.28 & 16.28 & $(.625)$ & 63.43 & 18.44 & $(.810)$ \\
\hline \multirow[t]{3}{*}{ Time since completion of cancer treatment (years) } & Less than 1 & 81.95 & 15.41 & 1.033 & 63.45 & 15.86 & 4.292 \\
\hline & $1-5$ & 87.13 & 14.02 & $(.360)$ & 65.00 & 15.40 & $(.015)$ \\
\hline & 5 or more & 82.22 & 17.36 & & 49.25 & 25.56 & $a, b>c$ \\
\hline
\end{tabular}

Note. SD Standard Deviation

Post-Hoc test: Tukey's test

\section{Discussion}

Mullen divided the stages of cancer survival into three major classifications [32, 33]. First is the acute stage, which marks the period after the cancer diagnosis. Second is the extended stage, in which the active treatment of cancer has ended and the patient is placed under tracking observation or engages in intermittent treatment. During this period, the majority of cancer survivors experience uncertainty toward their cancer treatment and fear recurrence, and they may experience physical and psychological issues. Lastly, the permanent stage marks a period in which the cancer is thought to be fully cured, or the patient is expected to survive long term, with a low risk of recurrence.

The participants in this study averaged a score of 66.90 for quality of life. As it is difficult to draw a direct comparison given the lack of research utilizing this measure, in converting quality of life into a scale of 100 points, this study's results were similar to those found previously regarding post-hoc management following 
Table 4 Differences in quality of life according to demographic and illness-related characteristics. $(N=148)$

\begin{tabular}{|c|c|c|c|c|c|}
\hline \multirow[t]{2}{*}{ Variable } & \multirow[t]{2}{*}{ Category } & \multicolumn{4}{|c|}{ quality of life } \\
\hline & & Mean & SD & tor $F$ & $p$-value \\
\hline \multirow[t]{4}{*}{ Age (years) } & Below 40 & 67.78 & 16.92 & 0.256 & .857 \\
\hline & $40-49$ & 68.02 & 20.27 & & \\
\hline & $50-59$ & 65.85 & 17.56 & & \\
\hline & 60 and over & 64.08 & 22.28 & & \\
\hline \multirow[t]{3}{*}{ Marital status } & Married & 66.67 & 19.25 & 0.170 & .844 \\
\hline & Single & 67.87 & 20.75 & & \\
\hline & Widowed or divorced & 65.43 & 14.75 & & \\
\hline \multirow[t]{2}{*}{ Education } & Less than high school & 68.06 & 20.31 & 0.563 & .574 \\
\hline & University and higher & 65.94 & 21.50 & & \\
\hline \multirow[t]{2}{*}{ Religion } & No & 64.82 & 20.65 & -0.896 & .372 \\
\hline & Yes & 67.95 & 20.18 & & \\
\hline \multirow[t]{3}{*}{ Having a job } & No & 65.35 & 21.79 & 1.845 & .162 \\
\hline & Loss of job & 61.33 & 22.55 & & \\
\hline & Yes & 69.65 & 18.22 & & \\
\hline \multirow[t]{3}{*}{ Satisfaction with economic status } & Satisfaction ${ }^{a}$ & 78.70 & 17.73 & 6.648 & .002 \\
\hline & Average $^{b}$ & 69.29 & 19.38 & & $a, b>c$ \\
\hline & Dissatisfaction $^{c}$ & 56.32 & 20.61 & & \\
\hline \multirow[t]{3}{*}{ Number of children } & No or 1 & 60.80 & 21.66 & 1.726 & .182 \\
\hline & 2 & 68.24 & 19.82 & & \\
\hline & 3 and over & 69.22 & 19.26 & & \\
\hline \multirow[t]{2}{*}{ Smoking status } & Current smoker & 57.29 & 32.26 & -0.906 & .394 \\
\hline & Non-smoker & 67.73 & 19.28 & & \\
\hline \multirow[t]{2}{*}{ Drinking status } & Current drinker & 67.00 & 20.88 & 0.015 & .988 \\
\hline & Non-drinker & 66.94 & 20.28 & & \\
\hline \multirow[t]{2}{*}{ Type of cancer } & Breast cancer & 69.84 & 20.16 & 0.114 & .267 \\
\hline & Thyroid cancer & 65.71 & 20.36 & & \\
\hline \multirow[t]{2}{*}{ Stage of cancer } & Early-stage cancer & 68.33 & 18.91 & 0.822 & .413 \\
\hline & Advanced stage cancer & 65.28 & 23.48 & & \\
\hline \multirow[t]{3}{*}{ Time since completion of cancer treatment (years) } & Less than 1 & 67.72 & 21.91 & 0.307 & .736 \\
\hline & $1-5$ & 64.52 & 16.94 & & \\
\hline & 5 or more & 65.97 & 13.51 & & \\
\hline
\end{tabular}

Note. SD Standard Deviation

Post-Hoc test: Tukey's test

Table 5 Correlations among uncertainty, social support, and quality of life. $N=148$

\begin{tabular}{|c|c|c|c|c|}
\hline \multirow[t]{2}{*}{ Variables } & \multicolumn{2}{|c|}{ Uncertainty in illness } & \multicolumn{2}{|c|}{ Quality of life } \\
\hline & $r$ & $p$-value & $r$ & $p$-value \\
\hline Uncertainty in illness & - & - & -.312 & .001 \\
\hline Social support (Total) & -.335 & $<.001$ & .321 & $<.001$ \\
\hline Family & -.244 & .010 & .265 & .001 \\
\hline Friends & -.294 & .002 & .284 & .001 \\
\hline Significant others & -.326 & .001 & .315 & $<.001$ \\
\hline
\end{tabular}

breast cancer treatment for 200 women $[8,10]$. However, a study covering regionally based, adult female breast cancer survivors between 6 months and 2 years after anti-cancer treatment completion reported lower scores (e.g., 60.13 points) compared to this study [27]. Likewise, a study of breast cancer survivors with completed surgeries and assistive treatments, breast cancer survivors whose treatment had ended had scores of 53.4 and 56.66 points, respectively for breast cancer survivors with completed surgeries and assistive treatments [25, 26]. 
Table 6 Mediating effect of social support in the relationship between uncertainty and quality of life. $N=148$

\begin{tabular}{|c|c|c|c|c|c|c|c|c|}
\hline Equations & $B$ & SE & $\beta$ & $t$ & $p$-value & Adj. $R^{2}$ & F & $p$-value \\
\hline 1. Uncertainty $\rightarrow$ Social support & -0.359 & 0.098 & -0.335 & -3.658 & $<.001$ & .104 & 13.380 & $<.001$ \\
\hline 2. Social support $\rightarrow$ QoL & 0.383 & 0.095 & 0.321 & 4.044 & $<.001$ & .097 & 16.351 & $<.001$ \\
\hline 3. Uncertainty $\rightarrow$ QoL & -0.396 & 0.117 & -0.312 & -3.379 & .001 & .089 & 11.417 & .001 \\
\hline 4. Uncertainty, Social support $\rightarrow$ QoL & & & & & & .121 & 8.322 & $<.001$ \\
\hline 1) Uncertainty $\rightarrow$ QoL & -0.308 & 0.123 & -0.241 & -2.500 & .014 & & & \\
\hline 2) Social support $\rightarrow$ QoL & 0.257 & 0.116 & 0.213 & 2.206 & .030 & & & \\
\hline Sobel test: $Z=-2.711, p=.007$ & & & & & & & & \\
\hline
\end{tabular}

On the other hand, a report of 110 adult females with breast cancer or OB/GYN cancers [33] indicated that quality of life according to cancer survival stage was 58.7, 62.3, and 66.8 points during the acute, extended, and permanent stages, respectively. Quality of life in this study was similar to the level experienced by survivors during the permanent stage. Considering that the average time since treatment was 17.64 months, these results indicate a relatively high quality of life. While these differences cannot be accurately compared and discussed because of the lack of research covering the same variables, the majority of survivors had thyroid cancer (70.9\%), and it is known that thyroid cancer has higher rates of survival. Going forward, it is important to develop interventions to improve quality of life by assessing survivors' specific stages.

There were no significant relationships between quality of life and length of time since completing treatment. Existing research has suggested that quality of life was significantly higher for those surviving more than 5 years after cancer treatment completion [8,33], indicating that quality of life improves as duration of survival increases. The quality of life of these cancer survivors has been reported to improve with the passage of time $[8,33]$. Therefore, cross-sectional and longitudinal studies are required in the future to identify quality of life by survival stage and changes in quality of life over time.
On the other hand, qualitative studies of Korean female cancer survivors have indicated that the significant others and families of female cancer survivors wanted them to return to their pre-cancer lives to take care of their spouses and children, indicated the demands on female cancer survivors in Korea to fulfill their roles as wives and mothers before fully recovering from cancer [33]. Thus, customized interventions by survival stage for female cancer survivors are needed along with further research on the relationships between cultural specificity, role conflicts imposed on survivors because they are women, and their quality of life.

The uncertainty toward illness of the participants in this study was similar to existing research in breast cancer patients undergoing chemotherapy averaged 83.08 [34] and female thyroid cancer patients [35]. On the other hand, the level of uncertainty faced by cancer patients prior to surgery averaged 81.43 in a study of cancer patients hospitalized for breast, thyroid, and bladder cancer [36], which was slightly lower than the value found in this study. This appears to be because female cancer survivors in this study were mostly in the extended stage, which comes after the active treatment of their cancer [32, 33]. Most cancer survivors face uncertainty toward cancer treatment and fear of recurrence $[8,32,33]$; thus, they experience a diverse range of physical and psychological problems [6, 7]. On the other

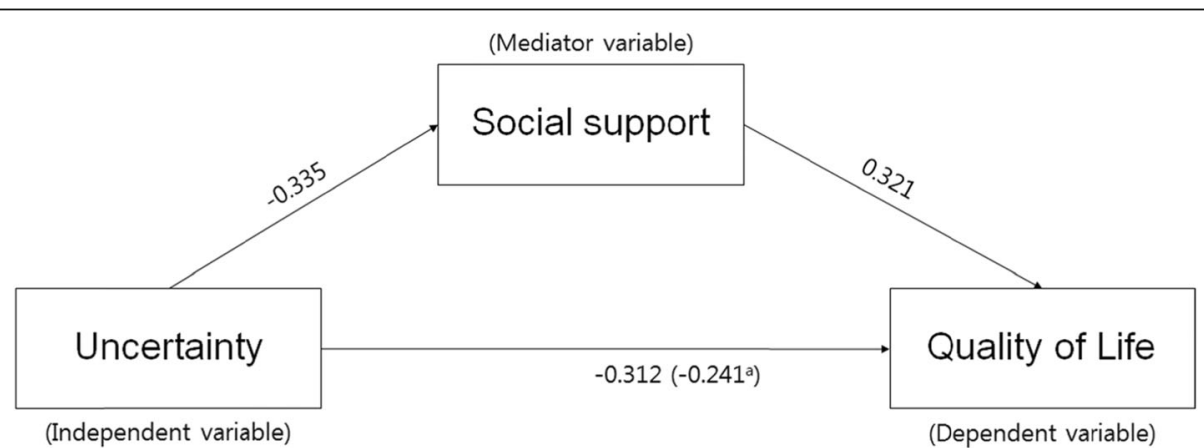

a : controlled social support

Fig. 2 Model showing the influence of uncertainty on quality of life and the mediating effect of social support 
hand, a qualitative study of 25 breast cancer survivors aged over 30 who had undergone surgery and chemotherapy as their primary treatment for breast cancer [37] indicated that quality of life following treatment for breast cancer survivors saw a coexistence of anxiety and uncertainty about recurrence. A shorter duration of time since treatment led to higher confusion in their own health management efforts and health management in general.

These results indicate that there are limitations to comparing uncertainty results given the lack of domestic studies on cancer survivors; therefore, future studies are needed to fill this gap. Moreover, it is necessary to confirm uncertainty by cancer survival stage and develop interventions to reduce the uncertainty accompanying each stage.

Uncertainty in illness was higher for those with less than a high school education, compared to those with a university education or higher, when they were dissatisfied with their financial status, and for those who were smokers. These results were similar to previous research [36], which indicated high uncertainty for participants over 60 who had a low monthly income and low level of education. Therefore, it is necessary to consider these socioeconomic factors when developing uncertainty reducing strategies such as customized information delivery and communication.

The social support of female cancer survivors in this study was rather high, at 62.62 out of 84 points; family support was the highest, followed by support from significant others, and finally friends. Social support is known to play an important role in helping individuals reduce their levels of uncertainty [37]. Particularly, in Korea, family and healthcare professional support have been the most important support resources among all social support types [34]. The results of this study indicated that family support was the highest, which was in line with the results of existing studies. On the other hand, a qualitative study of 25 breast cancer survivors aged over 30 who had undergone surgery and chemotherapy as their primary breast cancer treatments [37] indicated that positive support and responses from family, patients with similar illnesses, and those surrounding them helped to strengthen positive self-suggestion, which also helped them to overcome their illnesses. Other studies have reported that patients undergoing treatment receive active support from healthcare professionals and their family, but they receive less support and interest from healthcare professionals, their family, and those surrounding them after the treatment ends $[22,23,27]$. Therefore, it is necessary to take a continuous interest in and facilitate social support for cancer survivors.
Social support was higher for participants with average satisfaction toward their financial status, and for those for whom less than a year, or between 1 and 5 years, had passed since the completion of their cancer treatment, compared to those for whom 5 years or more had passed since treatment. These results were similar to those of studies on cancer patients hospitalized for breast, thyroid, and bladder cancer surgery [36], which indicated social support differed according to the time that had passed since diagnosis. Moreover, these results are similar to those reporting that breast cancer survivors are required by their spouses or family to fulfill roles they had filled prior to their cancer diagnosis, and this was associated with decreasing support from family [38]. These results indicate that female cancer survivors require ongoing psychosocial support as well as education and access to information as they live out their lives.

According to Baik and Lim [20], who studied social support according to different stages of breast and gynecological cancer survival, the social support of patients in the acute stage was comparatively higher, but there were no significant differences in social support across the different stages, which was different from the findings of this study. While there were no significant differences, Baik and Lim [20] reported that the social support perceived by survivors decreased as they proceeded through the acute to the extended stage. The social support perceived by respondents decreased in the 2 years following the diagnosis but maintained the reduced rate through the permanent stage [20]. Long-term survivors had a greater need to meet other cancer patients and self-help groups [20]. Kwon and Yi [27] asserted that interest and support from family and the society in general are very important in raising breast cancer survivors' quality of life and survival rates. Moreover, self-help groups were reported to be effective in providing emotional support for long- and short-term cancer survivors [39], which indicates the need for developing stage-specific social support interventions and various methods of facilitating social support groups. Moreover, further research is required concerning cancer survival stage-dependent social support and quality of life.

The results of this study showed that higher uncertainty in illness among female cancer survivors led to reduced social support and quality of life, while higher social support led to better quality of life. Support from others was found to be the most relevant aspect of the relationship between quality of life and uncertainty. These results were similar to those of studies on earlystage breast cancer patients [40] and on cancer patients hospitalized for breast, thyroid, and bladder cancer surgery [36], which indicated that perceived social support was lower as uncertainty increased. 
Uncertainty was very influential on female cancer survivors' quality of life. Higher uncertainty in illness among female cancer survivors led to lower social support and reduce quality of life; higher social support led to improved quality of life. The explanatory power of these variables on quality of life was $12.1 \%$; uncertainty in illness and social support influenced the quality of life of female cancer survivors. Moreover, in the process of uncertainty in illness influencing subjects' quality of life, social support was confirmed to play a significant, partially mediating, role in the relationship between uncertainty and quality of life. Higher uncertainty toward illness led to lower quality of life, higher social support led to higher quality of life, and social support influenced female cancer survivors' quality of life by partially mediating its relationship with uncertainty. Social support plays an important role in directly and indirectly reducing uncertainty $[18,19]$. Social support is closely related to the prognosis of breast cancer survivors [21]. Uncertainty among breast cancer survivors has been found to lower their quality of life; however, social support has been found to improve quality of life [11]. Thus, the need for a diverse range of attempts, including developing and applying social support programs, to increase cancer survivors' quality of life exists. On the other hand, the partially mediating effects of social support indicate that there are other mediating factors in uncertainty in illness's influence on quality of life. Therefore, it is important for future studies to include other mediating factors in their examinations of what influences quality of life among female cancer survivors.

In Korea, studies on cancer survivors have been conducted since 2010, and the majority of these focused on breast cancer survivors. Particularly, as there has been no overall research into the healthy behaviors of cancer survivors, it is necessary to develop practical guidelines that befit Korea through studies concerning the development and application of health improvement programs based on the study of healthy behaviors, as per the assertion of Kim [32]. Moreover, attempts are needed to practically apply a diverse range of intervention studies to improve cancer survivors' quality of life.

Moreover, future studies should include mediator variables other than social support that might influence quality of life. Additionally, both cross-sectional and longitudinal studies are needed to further investigate the quality of life and uncertainty according to the stages of survival.

\section{Conclusion}

Our results show that social support partial mediates the relationship between uncertainty and quality of life in female cancer survivors. The results of this study have great implications for improving cancer care, especially in how it relates to quality of life, and they also demonstrate how uncertainty can be decreased. Therefore, it is necessary to develop and apply intervention methods to improve social support thereby improving quality of life among female cancer survivors. A nurse-led social support program may especially contribute to enhancing the quality of life of cancer survivors by providing them with adequate health information and emotional support.

\section{Abbreviations \\ MUIS: Mishel's Uncertainty in IIIness Scale; MSPSS: Multidimensional Scale of Perceived Social Support; EORTC QLQ-C30: European Organization for Research and Treatment of Cancer Quality of Life Questionnaire Core 30; OB/ GYN : Obstetrics/Gynaecology}

\section{Acknowledgements}

We would like to thank Dr. Min, a physician of the Endocrine surgery at Cheju Halla Hospital, for collecting the data. And, we would like to thank the IRB who approved the research and the Editage Company who edited the English.

Conflict of interest

"No conflict of interest has been declared by the author(s)."

\section{Authors' contributions}

IL designed the study, searched the literature, analyzed the data, conducted the interpretation of data, drafted and edited the manuscript, and submitted the manuscript for publishing. CSP collected the data, searched the literature, and critically revised the initial manuscript. And all authors read and approved the final manuscript.

\section{Funding}

The authors did not receive any financial support for this study. This research did not receive any specific grant from funding agencies in the public, commercial, or not-for-profit sectors.

"This research did not received any specific grant from funding agencies in the public, commercial, or not-for-profit sectors."

\section{Availability of data and materials}

The data used in this study were collected through questionnaires and analyzed by coding the original data. The datasets generated and/or analysed during the current study are not publicly available due [REASON WHY DATA ARE NOT PUBLIC] but are available from the corresponding author on reasonable request.

\section{Ethics approval and consent to participate}

This study approved by IRB in Cheju Halla Hospital (IRB No. 2014-L02) and informed consent to participate.

\section{Consent for publication}

This manuscript has never been published in any other journal, and all authors agree to be published in this journal.

\section{Competing interests}

The authors declare that they have no competing interests.

\section{Author details}

${ }^{1}$ Department of Nursing, Changwon National University, C.P.O. Box 51140, Changwon, Republic of South Korea. ${ }^{2}$ Division of Nursing, Cheju Halla University, Jeju, Republic of South Korea.

Received: 8 December 2019 Accepted: 5 May 2020

Published online: 19 May 2020

\section{References}

1. Lee JE, Shin DW, Cho BL. The current status of cancer survivorship care and a consideration of appropriate care model in Korea. Korean J Clin Oncol. 2014;10(2):58-62. https://doi.org/10.14216/kjco.14012. 
2. Yoon HJ, Seok JH. Clinical factors associated with quality of life in patients with thyroid cancer. J Korean Thyroid Assoc. 2014;7(1):62-9. https://doi.org/ 10.11106/jkta.2014.7.1.62.

3. Dow KH, Ferrell BR, Leigh S, Ly J, Gulasekaram P. An evaluation of the quality of life among long-term survivors of breast cancer. Breast Cancer Res Treat. 1996:39(3):261-73. https://doi.org/10.1007/BF01806154.

4. Ferrell BR, Dow KH. Quality of life among long-term cancer survivors. Oncology. 1997;11:565-8.

5. Lee JE, Goo A, Lee KE, Park DJ, Cho B. Management of long-term thyroid cancer survivors in Korea. J Korean Med Assoc. 2016:59(4):287-93. https:// doi.org/10.5124/jkma.2016.59.4.287.

6. Molassiotis A, Yates P, Li Q, So WK, Pongthavornkamol K, Pittayapan P, et al. Mapping unmet supportive care needs, quality-of-life perceptions and current symptoms in cancer survivors across the Asia-Pacific region: results from the international STEP study. Ann Oncol. 2017;28(10):2552-8. https:// doi.org/10.1093/annonc/mdx350.

7. Yun YH, Kim YA, Sim JA, Shin AS, Chang YJ, Lee J, et al. Prognostic value of quality of life score in disease-free survivors of surgically-treated lung cancer. BMC Cancer. 2016;16(1):505-14. https://doi.org/10.1186/s12885-0162504-X.

8. Park JH, Jun EY, Kang MY, Joung YS, Kim GS. Symptom experience and quality of life in breast cancer survivors. J Korean Acad Nurs. 2009;39(5):61321. https://doi.org/10.4040/jkan.2009.39.5.613.

9. Chae YR. Relationships of perceived health status, depression, and quality of life of breast cancer survivors. J Korean Adult Nurs. 2005;17:119-27.

10. Kim YS, Tae YS. The influencing factors on quality of life among breast cancer survivors. J Korean Oncol Nurs. 2011;11(3):221-8. https://doi.org/10. 5388/jkon.2011.11.3.221.

11. Sammarco A, Konecny LM. Quality of life, social support, and uncertainty among Latina breast cancer survivors. Oncol Nurs Forum. 2008;35(5):844-9. https://doi.org/10.1188/08.ONF.844-849.

12. Liao MN, Chen MF, Chen SC, Chen PL. Uncertainty and anxiety during the diagnostic period for women with suspected breast cancer. Cancer Nurs. 2008;31(4):274-83. https://doi.org/10.1097/01.NCC.0000305744.64452.fe.

13. Dirksen S, Erickson J. Well-being in Hispanic and non-Hispanic Caucasian survivors of breast cancer. Oncol Nurs Forum. 2002;29(5):820-6. https://doi. org/10.1188/02.ONF.820-826.

14. Husson O, Haak HR, Buffart LM, Nieuwlaat WA, Oranje WA, Mols F, et al. Health-related quality of life and disease specific symptoms in long-term thyroid cancer survivors: a study from the population-based PROFILES registry. Acta Oncol. 2013;52(2):249-58. https://doi.org/10.3109/0284186X. 2012.741326.

15. Lee Jl, Kim SH, Tan AH, Kim HK, Jang HW, Hur KY, et al. Decreased healthrelated quality of life in disease-free survivors of differentiated thyroid cancer in Korea. Health Qual Life Outcomes. 2010;8(1):101. https:/doi.org/ 10.1186/1477-7525-8-101.

16. Yang J, Yi M. Factors influencing quality of life in thyroid cancer patients with thyroidectomy. Asian Oncol Nurs. 2015;15(2):59-66. https://doi.org/10. 5388/aon.2015.15.2.59

17. Oh KS. Social support as a prescription theory. J Nurs Query. 2006;15(1):13454

18. Lien CY, Lin HR, Kuo IT, Chen ML. Perceived uncertainty, social support and psychological adjustment in older patients with cancer being treated with surgery. J Clin Nurs. 2009;18(16):2311-9. https://doi.org/10.1111/j.1365-2702. 2008.02549.x.

19. Mishel MH. Uncertainty in illness. Image J Nurs Sch. 1988;20(4):225-32 https://doi.org/10.1111/j.1547-5069.1988.tb00082.x

20. Baik OM, Lim J. Social support in Korean breast and gynecological cancer survivors: comparison by the cancer stage at diagnosis and the stage of cancer survivorship. Korean J Family Soc Work. 2011;32(6):5-35.

21. Nausheen B, Kamal A. Familial social support and depression in breast cancer: an exploratory study on a Pakistani sample. Psychooncology. 2007; 16(9):859-62. https://doi.org/10.1002/pon.1136.

22. Alfano $\mathrm{CM}$, Rowland $\mathrm{JH}$. Recovery issues in cancer survivorship: a new challenge for supportive care. Cancer J. 2006;12(5):432-43. https://doi.org/ 10.1097/00130404-200609000-00012.

23. Ashing KT, Padilla G, Tejero JS, Kagawa-Singer M. Understanding the breast cancer experience of Asian American women. Psychooncology. 2003;12(1): 38-58. https://doi.org/10.1002/pon.632.

24. Janz $N$, Mujahid M, Chung L, Lantz P, Hawley S, Morrow M, et al. Symptom experience and quality of life of women following breast cancer treatment.
J Women's Health. 2007;16(9):1348-61. https://doi.org/10.1089/jwh.2006. 0255.

25. Min HS, Park SY, Lim JS, Park MO, Won HJ, Kim Jl. A study on behaviors for preventing recurrence and quality of life in breast cancer survivors. J Korean Acad Nurs. 2008;38(2):187-94. https://doi.org/10.4040/jkan.2008.38.2.187.

26. Kim GD. Impact of climacteric symptoms and fatigue on the quality of life in breast cancer survivors: the mediating effect of cognitive dysfunction. Asian Oncol Nurs. 2014;14(2):58-65. https://doi.org/10.5388/aon.2014.14.2.58.

27. Kwon EJ, Yi M. Distress and quality of life in breast cancer survivors in Korea. Asian Oncol Nurs. 2012;12(4):289-96. https://doi.org/10.5388/aon.2012.12.4. 289.

28. Baron RM, Kenny DA. The moderator-mediator variable distinction in social psychological research: conceptual, strategic, and statistical considerations. J Pers Soc Psychol. 1986;51 (6):1173-82. https://doi.org/10.1037/0022-3514.51.6. 1173.

29. Lee I. Uncertainty, appraisal and quality of life in patients with breast cancer across treatment phases. J Cheju Halla Collage. 2009:33:94-112.

30. Zimet GD, Powell SS, Farley GK, Werkman S, Berkoff KA. Psychometric characteristics of the multidimensional scale of perceived social support. J Pers Assess. 1990;55(3-4):610-7. https://doi.org/10.1080/00223891.1990. 9674095.

31. Fayers PM, Aaronson NK, Bjordal K, Groenvold M, Curran D, Bottomley A, On behalf of the EORTC Quality of Life Group. EORTC QLQ-C30 scoring manual. 3rd ed. Brussels: European Organization for Research and Treatment of Cancer; 2001. p. 2001.

32. Kim SH. Understanding cancer survivorship and its new perspectives.J Korean Oncol Nurs. 2010;10(1):19-29.

33. Lim J, Han I. Comparison of quality of life on the stage of cancer survivorship for breast and gynecological cancer survivors. Korean J Soc Welf. 2008;60(1):5-27. https://doi.org/10.20970/kasw.2008.60.1.001.

34. Ahn JY. The influence of symptoms, uncertainty, family support on resilience in patients with breast cancer receiving chemotherapy [master's thesis]. Seoul: The Seoul National University; 2014.

35. Lee I, Park CS. Convergent effects of anxiety, depression, uncertainty, and social support on quality of life in women with thyroid cancer. J Korea Convergence Soc. 2017;8(8):163-76. https://doi.org/10.15207/JKCS.2017.8.8. 163.

36. Park YJ. Uncertainty, anxiety and social support among preoperative patients of cancer: A correlational study [master's thesis]. Seoul: The Seoul National University; 2015

37. Yun M, Song M. A qualitative study on breast cancer survivors' experiences. Perspect Nurs Sci. 2013;10:41-51.

38. Ashing-Giwa KT. The contextual model of HRQoL: a paradigm for expanding the HRQoL framework. Qual Life Res. 2005;14(2):297-307. https:// doi.org/10.1007/s11136-004-0729-7

39. Adamsen L, Rasmussen J. Sociological perspectives on self-help groups: reflections on conceptualisation and social processes. J Adv Nurs. 2001; 35(6):909-17. https://doi.org/10.1046/j.1365-2648.2001.01928.x.

40. Kim HY, So HS. A structural model for psychosocial adjustment in patients with early breast cancer. J Korean Acad Nurs. 2012;42(1):105-15. https://doi. org/10.4040/jkan.2012.42.1.105

\section{Publisher's Note}

Springer Nature remains neutral with regard to jurisdictional claims in published maps and institutional affiliations.

Ready to submit your research? Choose BMC and benefit from:

- fast, convenient online submission

- thorough peer review by experienced researchers in your field

- rapid publication on acceptance

- support for research data, including large and complex data types

- gold Open Access which fosters wider collaboration and increased citations

- maximum visibility for your research: over $100 \mathrm{M}$ website views per year

At BMC, research is always in progress.

Learn more biomedcentral.com/submission 